\title{
Apuntes sobre la educación básica en el estado de Chihuahua de 1920 a 1950
}

\author{
Guillermo Hernández Orozco \\ Facultad de Filosofía y Letras, UACH \\ ghernand@uach.mx
}

\section{Resumen}

El derecho al acceso a la educación formal principalmente a nivel primaria fue uno de los postulados de la revolución mexicana, sin embargo el logro del mismo en el país se dificultó por la situación política, económica y social que se vivió en las décadas posteriores al término del movimiento armado. Solo una parte de la población, principalmente del medio urbano, tenía acceso a la educación y la mayor parte de la misma no concluía sus estudios primarios. Esta situación favorecía la reproducción de la pobreza en las familias al no tener una educación que les permitiera acceder a mejores oportunidades laborales. Este trabajo presenta algunos datos que revelan parte del proceso a través del cual la educación formal en el estado de Chihuahua amplió su cobertura así como algunos factores que constituyeron resistencia en los pobladores para ser beneficiarios del servicio educativo. El escrito hace referencia en particular a la población de Parral cuyos datos que se obtuvieron al realizar una tesis en la línea de investigación de historiografía. Las fuentes consultadas fueron actas de cabildo, documentos y periódicos del Archivo Histórico Municipal de Parral, así como algunos autores chihuahuenses cuyos textos se encontraron en el Archivo Histórico de la Universidad Autónoma de Chihuahua.

\section{Palabras clave}

Educación básica, deserción escolar, ausentismo escolar, educación en Chihuahua.

\section{Introducción}

La historiografía de la educación rescata datos que permiten la reconstrucción de la situación educativa que se vivía en el pasado así como su contexto socioeconómico y brinda elementos que permiten analizar tales hechos. Los anuarios estadísticos, censos e informes de gobierno son instrumentos que permiten reunir tal información.

Los datos presentados por De la Peña (1948: 170) muestran un aumento considerable en el número de niños atendidos en las escuelas de gobierno así lo indica el siguiente cuadro.

Tabla 1. Alumnos atendidos en escuelas oficiales en el estado de Chihuahua de 1924 a 1944

\begin{tabular}{|l|l|l|}
\hline Año & Escuelas & Alumnos \\
\hline 1924 & 398 & 30,811 \\
\hline 1940 & ---- & 81,237 \\
\hline $1943-44$ & 1,068 & 87,124 \\
\hline
\end{tabular}


Sin embargo ante tal avance en la cobertura del servicio educativo este mismo autor indica que en el censo de 1944 la población escolar en el estado de Chihuahua no bajaba de 135,000; en este mismo año hubo una matrícula de 87,124 en consecuencia se quedaban sin matricular 48,000 niños que representa el $35 \%$ del total; es importante recalcar que de los alumnos inscritos la mayoría de ellos abandonaba la escuela antes de los 12 años.

El problema de la deserción escolar se acentuaba en el medio rural donde se presentaba un desajuste entre las necesidades del trabajo del campo y las vacaciones escolares normadas por un calendario escolar.
Un ejemplo de ello es Guadalupe y Calvo, municipio serrano de Chihuahua en cuya cabecera municipal tenía en $1^{\circ} 46$ niños, en $2^{\circ}$ $34,3^{\circ} 21$ alumnos, $4^{\circ} 16,5^{\circ} 13$ y $6^{\circ} 6$ alumnos repitiéndose la situación en las rancherías de los estados.

En 1940 se requerían según Peña 400 plazas de maestros para cubrir vacantes, abrir escuelas cerradas y crear escuelas faltantes donde hubiera 15 niños o más en edad escolar. En el medio rural se contaba por docenas los poblados con un solo maestro para $100 \mathrm{y}$ hasta 200; los inspectores escolares no conocían la mayoría de las escuelas de su zona.(De la Peña, 1948: 176).

Tabla 2. Movimiento de alumnos en 1950 en el estado de Chihuahua (Anuario Estadístico,1950: sp).

\begin{tabular}{|l|l|l|l|l|l|}
\hline & Inscritos & Bajas & Existencia & Aprobados & $\begin{array}{l}\text { Asistencia } \\
\text { media anual }\end{array}$ \\
\hline Jardín de niños & 4,237 & 354 & 3878 & 3646 & 3395 \\
\hline Incorporados & 246 & 16 & 230 & 223 & 218 \\
\hline Primaria & 72,449 & 9,549 & 62,900 & 48,295 & 56,560 \\
\hline Incorporados & 2,743 & 230 & 2,513 & 2,268 & 2,523 \\
\hline $\begin{array}{l}\text { Alumnos } 6^{\circ} \text { de } \\
\text { Escuela oficial }\end{array}$ & 3,944 & 375 & 3,569 & 3,269 & 1,839 \\
\hline $\begin{array}{l}\text { Alumnos } 6^{\circ} \text { de } \\
\text { Esc.incorporada }\end{array}$ & 222 & 11 & 211 & 202 & 196 \\
\hline
\end{tabular}

\section{Contexto educativo en la década de los 50}

Según datos de este cuadro en sexto grado de las escuelas oficiales solo el $51.5 \%$ de los alumnos inscritos asistía a tomar clases regularmente aún y cuando un porcentaje alto era aprobado, casi la mitad de los niños no asistían a clases. Este dato se ve reflejado en Parral en donde según acta de cabildo de 1950 los regidores acuerdan nombrar un policía escolar que vigile que los escolares no estén en la calle durante el horario escolar para evitar la deserción y el vandalismo alejándolos también de los juegos de azar y centros de vicio (A.H.M.P. Actas de cabildo, 5 de enero de 1950).

De nuevo en enero de 1953 el Presidente municipal de este ciudad expresa que es un serio problema la vagancia infantil y 
solicita el apoyo de los inspectores escolares de las zonas federal y estatal para que los niños no vaguen en las calles en horario de clase; gira también un oficio a gerentes de cines para prohibir la venta de boletos a niños en horario escolar además los regidores acuerdan nombrar un inspector escolar que vigile la ciudad prohibiendo hasta donde sea posible la vagancia infantil (A.H.M.P. Actas de cabildo,1 de enero de 1953). (Por lo que se deduce que no se dio seguimiento al policía escolar acordado en 1950)

De nuevo ante los regidores el mismo año de 1953 el presidente municipal expone lo delicado del problema de la delincuencia infantil ya que se han organizado verdaderas bandas que cometen delitos del fuero común y que por ser menores de edad las autoridades legalmente no están capacitadas para aplicar sanciones por lo que es indispensable acondicionar un lugar en donde se puedan recluir y de alguna forma instruirlos para evitar que sigan el camino de la delincuencia (A.H.M.P. Actas de cabildo,7 de enero de 1953).

Los regidores retoman el tema de la deserción infantil en 1956 y acuerdan facultar al policía escolar para que detenga a los niños que transitan en la calle en horario de clase. (A.H.M.P. Actas de cabildo 2 de enero de 1956). El problema de los menores infractores es un tema que afecta a la sociedad parralense por ello es tratado en varias ocasiones a reuniones de cabildo. En documento encontrado en el Anuario Estadístico da los siguientes datos sobre los delitos más frecuentes.

Tabla 3. Presupuesto dedicado a la educación en el estado de Chihuahua (Anuario Estadístico, $1950 \mathrm{sp}$ )

\begin{tabular}{|l|l|l|l|l|l|l|l|l|}
\hline 1942 & 1943 & 1944 & 1945 & 1946 & 1947 & 1948 & 1949 & 1950 \\
\hline $22.28 \%$ & $26.41 \%$ & $23.19 \%$ & $29.13 \%$ & $31.29 \%$ & $32.35 \%$ & $35.27 \%$ & $35.06 \%$ & $39.44 \%$ \\
\hline
\end{tabular}

\section{Presupuesto destinado a la educación}

Al presentar los datos el autor indica que el territorio del estado de Chihuahua es muy disperso y por ello no "rinde" el presupuesto. Ciertamente era insuficiente ante las necesidades educativas de la población.(de la Peña, 1948: 174) Expresa que el dinero destinado en 1943 a la educación no es para la dotación de materiales, muebles o útiles escolares, de los que hay una carencia angustiosa en casi la totalidad de las escuelas , sino para la construcción de edificios escolares en lo que aún resta mucho por hacer, pero en vista de que el fardo del analfabetismo es todavía tremendamente desconsolador, se cree que en lugar de dotar de bellos y adecuados edificios urge dotar al pueblo con las escuelas que hacen falta, así sea en locales defectuosos, como se ha venido haciendo con éxito desde 1920, y una vez satisfecha la necesidad primaria vendrá la dotación de buenos edificios, buen mobiliario y maestros competentes, titulados y bien remunerados. Es tan basto el problema que expresa la preocupación inicial de ocuparse de la cantidad luego de la calidad. Por docenas se contaban rancherías en donde los campesinos construían su edificio escolar; algunos hacían el esfuerzo de pagar a los maestros, pero en años difíciles la escuela cerraba.

No solo en el medio rural la carencia de escuelas era preocupante, también en las localidades urbanas. En reunión de cabildo celebrada en Parral en 1947 el regidor de educación presentó una relación sobre el funcionamiento de las escuelas estatales: 99, 103, 56, 112 y 101 indicando que en ellas funcionan deficientemente los servicios de 
agua y drenaje. El ayuntamiento se compromete a realizar las reparaciones de los servicios e indica que invitará a los padres y maestros de cada plantel para que colaboren (A.H.M.P. Actas de cabildo. 23 de enero de 1947).

Ante la carencia de edificios escolares en 1948 en Parral se optó por rentar casas para que funcionaran como escuelas, se tiene registro de ello en la solicitud realizada por Angela Peralta quien mediante oficio solicita al ayuntamiento la devolución de la casa que les tenía rentada como escuela y pide apoyo moral y material para la colonia Morelos a fin de que puedan tener su escuela. En la misma reunión se trata el asunto de la escuela 118 en la cual la sociedad de padres y maestros solicita ayuda para terminar de construirla, a cuya petición contestan que se apoyará en la medida de las posibilidades del municipio mediante el comité pro construcción y reconstrucción de escuelas (A.H.M.P. Actas de cabildo, 12 de enero de 1950).

Además de las escuelas oficiales había escuelas particulares a las cuales no tenía acceso el grueso de la población; en el periódico de la localidad de 1948 se publicó una nota publicitaria de la escuela Justo Sierra anunciando " este plantel es el único que campea con las energías para hacer que los niños cumplan con su deber", en el mismo periódico se anuncia la escuela Lydia Patterson institute de El Paso Texas que invita a su institución con la siguiente frase "donde la atmósfera es la de un hogar" (El Correo de Parral, 19 de agosto de 1948). Por el texto de las frases la escuela de El Paso ofrecía la escuela como una extensión del hogar en donde los alumnos asisten para ser atendidos, la academia de Parral plantea la escuela cuya base de la formación es la disciplina, "campeando sus energías" es decir, canalizando sus energías sin lastimarlos, puesto que en escuelas oficiales eran comunes los castigos y golpes como forma de control ya que los maestros atendían grupos de 60 ó más alumnos.

En el periódico "El Correo de Parral" (El Correo de Parral, 19 de agosto de 1948 nota escrita por Fidel Solís), se publicó una nota en 1948 que resume las expectativas puestas en la educación: " la obra gigantesca que nuestro país realizará en cuatro años para levantar las escuelas necesarias requerirá de 24,000 maestros y costará 5 millones de pesos ...la enseñanza tendrá nuevas orientaciones y programas al ritmo de las necesidades pedagógicas en una cruzada contra la ignorancia con las armas inmejorables que no se mellan... México necesita preparar a los soldados (maestros) para tener mejor éxito en la campaña, la enseñanza que se imparta en los establecimientos normales deberá ser amplia y fácil; Anteriormente México tenía que improvisar todo; después de la turbulencia de las guerras civiles, el maestro fue más con su entusiasmo que con su técnica a rescatar de la ignorancia a los que en siglos no habían tenido más miradas que del sufrimiento y la miseria. Ahora los tiempos han cambiado, los niños estarán mejor preparados; la preparación de los maestros será otra victoria del estado en esta campaña que se hace por la escuela y la generación".

\section{A manera de conclusión:}

El problema de la baja escolaridad tenía múltiples facetas: falta de escuelas y carencia de maestros en los planteles ya construidos, alumnos que no querían asistir a clase, padres que preferían que sus hijos les ayudaran trabajando. La cobertura del servicio educativo definitivamente no fue a la par con las necesidades de educación, los grupos vulnerables fueron los últimos en acceder a este servicio.

La ampliación en la cobertura del servicio educativo tuvo otros fines que iban más allá del aprendizaje académico del alumno. Dadas las condiciones de represión 
en la ciudad de Parral así como en otros lugares en los que surgió la figura del policía escolar la escuela primaria es vista por el Estado más que un medio para la educación de los alumnos como un instrumento de control social para evitar la vagancia y delincuencia así como para formar hábitos de disciplina, trabajo, honestidad, obediencia. La escuela pretendía formar ciudadanos respetuosos de las normas que no cuestionaran el orden social y económico de la época.

\section{Referencias}

De la PEÑA Moisés.1948. "Chihuahua económico" Tomo I Departamento de Economía, sección publicidad . Lic. Oscar Soto Maynez, gobernador.

PONCE de León José María. Anuario Estadístico del estado de Chihuahua $1945-1950$

A.H.M.P. Acta de cabildo 7 de enero de 1953

A.H.M.P. Acta de cabildo, 5 de enero de 1950.

A.H.M.P. Actas de cabildo 2 de enero de 1956

A.H.M.P. Actas de cabildo, 12 de enero de 1950 
RECIE. Revista Electrónica Científica de Investigación Educativa Vol. 1, núm. 1, enero-diciembre 2012, pp. 17-21.

Hernández Orozco, G. 